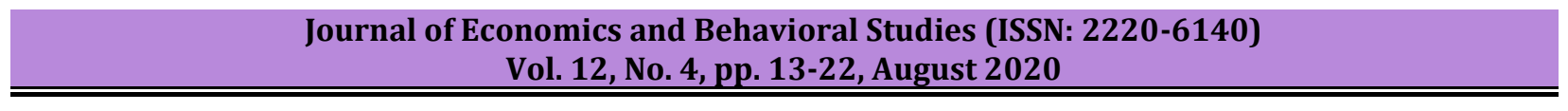

\title{
The Role of Computer Education in the Behavioural Intentions to Use Information Technology in Hospitals in Kumasi, Ghana
}

\author{
Ernest Osei, Peter Kwasi Oppong \\ University of KwaZulu-Natal, Durban, South Africa \\ ernestosei56@gmail.com, peteroppong72@gmail.com
}

\begin{abstract}
Computer education is increasing steadily because it is well-recognized as a major indicator of the successful acceptance of information technology applications in an organization. Despite the advantages associated with computer education, there is a relative scarcity of empirical studies on the potential role of computer education in the behavioural intentions of staff to use information technology applications, particularly in healthcare settings. Thus, this research is aimed to investigate the role of computer education to the behavioural intentions of staff to use information technology applications in the hospitals in Kumasi. Guided by Davis` technology acceptance model, five hypotheses were stated and examined through structural equation modeling. Utilizing stratified sampling, data were gathered via a survey questionnaire from a sample of 154 staff in the hospitals in Kumasi. The research revealed that computer education contributes positively to the behavioural intentions to use via the impact of perceptions of ease of use of technology applications in the hospitals in Kumasi. The research, therefore, recommends that the management should consider computer education in the adoption of technology systems to enhance the staff perceptions of ease of use and hence, their intentions to use to improve health care in the Metropolis.
\end{abstract}

Keywords: Computer education, Behavioural intentions, Information technology, Hospitals.

\section{Introduction}

Quality healthcare delivery remains one of the many challenges facing less developed countries, particularly in sub-Saharan Africa. As a result of this, many countries have taken several steps to enhance health infrastructure, enrolment in healthcare organizations, and information technology (IT) applications to satisfy the health needs of the populace. Information technology mainly deals with information in an electronic form which includes its accessibility, processing, storing, transporting, or transferring as well as its delivery (Laudon \& Laudon, 2000). It has been highlighted that intensive adoption of IT in the healthcare delivery can improve data security, save cost and time as well as facilitate the accessibility of patients' data (Miller, Elixhauser, Zhan \& Meyer, 2001). In Ghana, most health facilities are using IT to capture, store, process, and transmit data connected to patients' health or the daily activities of health professionals (MOH, 2009). Burton-Jones and Hubona (2006) pointed out that computer education plays an immense role in the successful adoption of IT applications.

The authors further contended that computer education can contribute to improving the perceived ease of use (PEOU) and perceived usefulness (PU) and hence, the volume of use of IT applications in an organization. Despite the potential role of computer education in the adoption of IT systems, there is a relative scarcity of empirical studies to evaluate the influence of computer education on the intentions of staff to use IT applications, particularly in the healthcare industry. However, similar research investigated the potential role of external factors such as computer education, age, and experience on the volume of use of information technology applications (ibid). Consequently, this research is set out to evaluate the impact of computer education on the behavioural intentions of staff to use IT systems in the hospitals in Kumasi Metropolis. In this respect, the paper expands the current theory on the importance of computer education to the technology acceptance models, particularly in the health care organizations. Moreover, the paper contributes to the practical knowledge of health care providers on the potential role of computer education in the acceptance of IT in the healthcare facilities in Kumasi.

\section{Literature Review}

Information Technology: The provision of excellent services is recognized as one of the priorities of the healthcare industry. It has been pointed out that IT provides multiple benefits to patients, healthcare providers as well as the government at large (Miller et al., 2001). The authors further noted that the adoption 
of IT can assist healthcare providers to access the health records of patients from all departments and units within a facility. This can offer health care providers a platform to improve on their clinical decisions, manage disease and documentation as well as the quality of time spent with patients. Stol, Ehrenfeld, and Epstein (2014) defined IT as the usage of computers and their software in managing and manipulating information. Alternatively, Laudon and Laudon (2000) stated that IT is much bigger than the traditional personal computer and network technologies which include the co-ordination of other technologies like the usage of mobile phones, television sets, etc. Johnson (2003) noted that IT was introduced into the healthcare delivery as Hospital Information Systems and Physician Management Systems in the early part of 1970, and since then it has evolved to sharing of systems. Currently, the IT infrastructure includes computer equipment, networking accessories, multi-media applications, mobile communication services, imaging, and internet systems (MOH, 2009). A nation-wide area network (WAN) has also been introduced to enhance telecommunication infrastructure in the health care units (ibid).

However, few of these healthcare units have introduced local area network (LAN) to provide automated financial and pharmaceutical services as well as front desk activities like registration of patients and keeping of records. Added, telemedicine is not well-developed in the healthcare system in the country. Despite these few developments in healthcare delivery, most of the IT applications have not been fully integrated in a way that will improve healthcare services in the country (ibid). It has been suggested that four major factors have stifled the successful use of IT in the health services industry (Abookire et al., 2000). First, situational elements such as time and financial pressure, and unaccounted returns with regards to investment and internet which are not accessible in the offices' environment. The second relates to the cognitive and/or physical environment, which among other things includes computer illiteracy or training. Liability is another obstacle which involves confidentiality issues in the final knowledge. Finally, attitudinal factors like inadequate research, resistance to change, and ignorance of the benefits of IT applications. Kaye, Kokia, Shalev, Idar, and Chinita (2010) also suggested that business and financial, structural, cultural, technical and professionals are some of the challenges of acceptance of IT applications in the health service delivery. Finally, changes and adverse disruptions of normal clinical workflow and routine work make health professionals to reluctantly accept IT in their normal routine activities (Ajami \& Arab-Chadegani, 2013).

Technology Acceptance Model: Extant literature indicates that technology acceptance models (TAMs) have been widely adopted to evaluate the acceptance of IT applications in many industrial settings including healthcare. Past studies also revealed that TAMs are the best models to evaluate the determinants of adoption of IT applications (dos Reis \& Freitas, 2014; Noblin, Wan \& Fottler, 2013). A similar study posited that TAMs can be used to model variables such as attitudes, satisfaction, predictions, and usage built on beliefs and other external factors (Al-Gahtani \& King, 1999). A review of the literature also reveals that many researchers have developed different models for technology acceptance and other behaviors with regards to the usage of IT applications. However, the most important TAM which has been well-documented in the literature is Davis' (1989) TAM (Burton-Jones \& Hubona, 2006; Hennington \& Janz, 2007; Legris, Ingham \& Collerate, 2003). According to this Model, perceived ease of use (PEOU), perceived usefulness (PU), actual system use, behavioural intention to use (BITU), and attitudes are the main elements of acceptance of IT applications. The model further indicated that user`s perceptions to accept IT applications can be explained by PEOU, PU.

Attitude towards the usage of such IT systems, PU and PEOU are influenced by external variables including political, social, and cultural elements. However, a study revealed that external factors comprising objective system design characteristics, training, computer self-efficacy, user involvement in the design, and the nature of the implementation process can also influence PEOU and PU. These external elements affect BITU and ultimately, usage indirectly through their impact on PEOU and PU (Davis \& Venkatesh, 1996). Alternatively, Burton-Jones and Hubona (2006) identified some external elements consisting of computer education, age, and system experience as determinants of adoption of IT applications through the impact of PEOU and PU. In this research, however, TAM proposed by Davis (1989) was adopted because it has been widely accepted and used in many research contexts such as healthcare industry (Kijsanayotin, Pannarunothai \& Speedie, 2009; Hennington \& Janz, 2007; Wu, Wang \& Lin, 2007); government agencies (Lean, Zailani, Ramayah \& Fernando, 2009) and banking industry (AbuShanab \& Pearson, 2007). Moreover, it has been asserted that Davis' model provides the best framework with well-defined variables that can enhance users' perceptions and behaviors towards IT applications (Handy, Hunter \& Whiddat, 2001). 
Study Conceptual Framework: Here, the purpose is to provide a narrative and graphical explanation to the key constructs used and their posited relationships (Miles \& Huberman, 1994). Based on the literature review, the main constructs that are considered in the adoption of IT applications in the hospitals in Kumasi are computer education, PEOU, BITU, and PU. In this paper, computer education is operationalized as knowledge gained from IT applications. PEOU also measures how the users understand and appreciate the comfortability of working with IT applications. PU is concerned with the degree at which users appreciate the usefulness and benefits of using IT applications, whilst BITU measures the users ' willingness to undertake a task to achieve targeted performance. The conceptual framework is depicted in Figure 1 below which shows that computer education is considered as an independent variable, PU and PEOU are mediating variables and BITU is regarded as the dependent variable. The level of computer education affects BITU through the mediating role of PEOU and PU. However, PEOU directly influences PU which, in turn, affects BITU.

\section{Figure 1: The Study Conceptual Model}

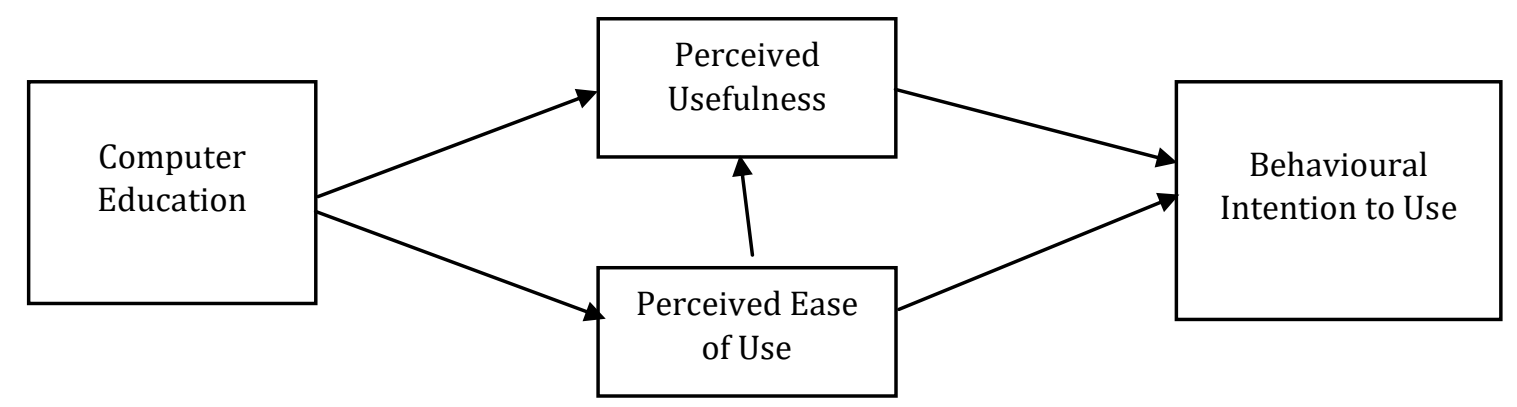

Source: Developed by the Researchers

Research Hypotheses: Guided by the conceptual framework, the proposed hypotheses in this research are discussed below.

Computer Education: Computer education relates to the level of knowledge users have acquired in IT applications (Burton-Jones \& Hubona, 2006). In the adoption of an electronic system into any organization such as healthcare, the level of knowledge of the staff in IT should be considered. If staff possesses a certain level of knowledge and capability in IT, they will have the intention to use such a system. Zmud (1976) cited by Burton-Jones and Hubona (2006) contended that a high level of users' education positively affects their success in using IT. The author further stated that an increase in computer education would improve users' attitude and reduce anxiety, and also offer a pool of knowledge that can lead to effective and adaptive learning. It has also been highlighted that PEOU and PU are significantly influenced by computer education (Burton-Jones \& Hubona, 2006). A study also indicates that an increase in the level of computer education positively influences PEOU (ibid). Hence, the posited hypotheses are that:

H1: There will be a significant and direct relationship between computer education and PEOU

H2: There will be a significant and direct relationship between computer education and PU

Perceived Ease of Use: PEOU relates to how the users understand and appreciate the comfortability of using IT applications (Davis, 1989). According to the author, to keep IT application usage alive and friendly, the users should have functional interfaces that are easily accessible and of simple usage. It has also been highlighted that objective usability, computer playfulness, self-efficacy, anxiety, perceived external control and enjoyment have a greater influence on PEOU (Venkatesh \& Davis, 2000). The authors are also of the view that PEOU positively influences PU since an electronic system that requires less effort to use can be said to be useful. PEOU also contributes to increasing users' BITU. This is because the less effortful the usage of IT is, the more the users would exhibit a positive attitude towards it. Prior research also revealed that PU is positively affected by PEOU of IT applications (ibid). Consequently, the following hypotheses are stated:

H3: There will be a significant and direct relationship between PEOU and BITU

H4: There will be a significant and direct relationship between PEOU and PU 
Perceived Usefulness: PU measures how well the usage of a particular electronic application can improve job performance (Surendran, 2012). It has also been pointed out that social and cognitive variables can influence the PU of the IT system (Venkatesh \& Davis, 2000). The cognitive variables include output quality, job relevance, PEOU, and result demonstrability, whilst the social variables are the social norm, image, and voluntariness. However, PU is well-recognized as a dominant indicator of BITU (Venkatesh \& Davis, 2000; Surendran, 2012). Past research also found that PU enhances BITU (Venkatesh \& Davis, 2000). Consequently, the hypothesis stated is that:

H5: There will be a significant and direct relationship between PU and BITU

Behavioural Intentions to Use: BITU relates to the preparedness of a person to work with an IT application (Surendran, 2012) to achieve a performance target. BITU is recognized as a major determinant of the adoption of IT applications in an organization. Studies in psychology and TAM revealed that BITU is a key determinant of actual system usage. It has also been suggested that PEOU and PU influence BITU through the mediated effect of users` attitudes towards IT applications (Davis, 1989; Venkatesh \& Davis, 2000). Ajzen (1991) also pointed out that the greater the intention to put up behaviour, the more likely it will be performed. Moreover, if staff thinks that the adoption of technology application is very useful in his line of duty, he will intuitively have an intention to use it. Furthermore, if the staff has a positive attitude towards the usage of the IT system, his intention to use would increase (ibid).

\section{Research Methodology}

Scale Items Development: Here, the methods used to achieve the aim and for that matter, the research hypotheses are discussed below. This paper utilized survey questionnaires with five Point-Likert Scale where (1) represents strongly agree and (5) strongly disagree with the view to obtaining the healthcare professionals' perceptions on the level of computer education, BITU, PU, and PEOU. Three scale items were developed to measure computer education, six for PU, four for PEOU, whilst four for BITU were taken from Peker (2010) and adapted. The research used survey questionnaires because the data generated allow for better mathematical calculations and interpretations (Creswell, 2014; Mackenzie \& Knipe, 2006).

Sample and Data Collection Procedure: The study targeted nine (9) hospitals out of which five (5) were public and four (4) were private hospitals in the Metropolis (KMA, 2018). Three (3) of these hospitals (2 public and 1 private) were purposively selected because they had full computerized IT applications. These hospitals were Kwame Nkrumah University of Science and Technology (K.N.U.S.T), Kwadaso Seventh Day Adventist (S.D.A), and Kumasi South hospitals. According to the 2018 staff records of these hospitals, 255 health professionals utilized IT applications. Out of this number, one hundred and ten (110), one hundred (100) and forty-five (45) worked at K.N.U.S.T, Kwadaso S. D. A., and Kumasi South hospitals respectively. Guided by Krejcie and Morgan (1970) sample size model, 154 health professionals who utilized IT applications were included in the study. Besides, a stratified sampling procedure was employed to pick the respondents. This procedure allows the population to be divided into separate groups. A simple random sampling is then utilized to draw elements from each group (Malhotra \& Birks, 2007). This sampling method was used to ensure that each segment of the population is fairly represented in the sample selection procedure (ibid).

Research Results: A total of 154 distributed questionnaires were received but 7 were found to be incomplete. One hundred and fifty-four (154) questionnaires were distributed face-to-face to the healthcare professionals and other allied professionals in the three selected hospitals in the Metropolis. Sixty-seven (67), sixty (60), and twenty-seven (27) questionnaires were distributed to the respondents from the K.N.U.S.T, Kwadaso S.D.A and Kumasi South hospitals respectively. The profile of the research participants shows that out of a sample of 146, $67(47.2 \%)$ were male and 75 (52.8\%) were female. Also, 61 (41.8\%) were between the age of 20 and 30 years, $65(44.5 \%)$ was at the age of 30-40 years, $15(10.3 \%)$ were between the age of 41 and 50 years and $5(3.4 \%)$ was at the age of 51-60 years. Moreover, 7 (5\%) had a high school education, 42 (29.8\%) had diploma education, $25(17.7 \%)$ had a first degree and $67(47.5 \%)$ had a post-graduate degree. Finally, $19(13 \%)$ of the respondents were physicians, 45 (30.8\%) were nurses/midwives, 12 (8.2\%) were pharmacists, $22(15.1 \%)$ were administrators, 20 (13.7\%) were laboratory technicians and other staff were 
$28(19.2 \%)$. This demonstrates that the majority of the personnel working in these hospitals was female and nurses/midwives, between 20 and 30 years, and had post-graduate education.

Psychometric Properties of Scale Items: Consistent with prior research (Atilgan, Aksoy \& Akinci, 2005; Oppong \& Phiri, 2019), the psychometric measures of the scale items were validated via exploratory factor analysis (EFA), Cronbach alpha and confirmatory factor analysis (CFA). The measurement model was performed via CFA by using SPSS Amos 22. The CFA aimed to confirm the findings of the EFA and also to assess the discriminant and convergent validity.

Exploratory Factor Analysis: The EFA was conducted to check the extent to which the scale items load on their purported constructs to yield computer education, PEOU, PU, and BITU to provide support for construct validity (Atilgan et al., 2005). Seventeen (17) test instruments were subjected to the EFA. Kaiser-Meyer-Olkin (KMO) Measure of Sampling Adequacy was used to check whether the sample size is satisfactory for the successful conduct of the EFA. The results of the EFA presented in Table 1 below indicate that the sample size was satisfactory because the value of the KMO was .889, which is above the proposed .60 (Pallant, 2013). Moreover, the EFA was supported by the results of Bartlett's Test of Sphericity (Hair, Black, Babin \& Anderson, 2010). The EFA via the maximum likelihood factoring produced four distinctive factors.

Where factor 1 represents BITU, 2 is PU, 3 is computer education and 4 is PEOU. Overall, 11 scale items loaded well on their respective constructs. The factor loadings ranged between .343 and .933, while loadings less than .30 were dropped (Floyd \& Widaman, 1995). Moreover, all the four factors had eigenvalues above one, and also explained $66.536 \%$ of the total variance. To confirm construct validity, the factor loading of each test instrument on its purported variable exceeded the cross-loadings on any other variables (Hair et al., 2010). Cronbach alpha was employed to examine the scale items' reliability. The findings from Table 1 showed that computer education, PEOU, BITU, and PU had coefficients above the recommended cut-off of .70, ranging between .731 and .885, which indicate good reliability (Tavakol \& Dennick, 2011).

Table 1: Results of Exploratory Factor Analysis

\begin{tabular}{|c|c|c|c|c|c|}
\hline \multicolumn{2}{|c|}{ Test Items } & \multicolumn{4}{|l|}{ Factors } \\
\hline & & & 2 & 3 & 4 \\
\hline BEH19 & $\begin{array}{l}\text { I will use Information technology for patient care and } \\
\text { management }\end{array}$ & .386 & & & \\
\hline BEH20 & If I am given the opportunity, I will use information technology & .506 & & & \\
\hline PER 5 & $\begin{array}{l}\text { Information technology allows me to have much more control } \\
\text { over the work I do }\end{array}$ & & .933 & & \\
\hline PER 6 & Information technology enables me to work faster & & .751 & & \\
\hline PER7 & $\begin{array}{l}\text { Information technology improves the accuracy of my } \\
\text { performance }\end{array}$ & & .834 & & \\
\hline PER8 & Information technology enhances my effectiveness on the job & & .569 & & \\
\hline PER9 & $\begin{array}{l}\text { Information technology enables me to make precise decisions } \\
\text { based on available data }\end{array}$ & & .564 & & \\
\hline LIT1 & I have adequate knowledge of information technology & & & .584 & \\
\hline LIT2 & $\begin{array}{l}\text { I feel reluctant to use information technology for fear of } \\
\text { making mistakes which cannot be corrected }\end{array}$ & & & .510 & \\
\hline EAS16 & $\begin{array}{l}\text { Interaction of data with information technology makes it easy } \\
\text { to understand }\end{array}$ & & & & .343 \\
\hline EAS17 & Overall, I find information technology very easy to use & & & & .443 \\
\hline Cronbac & Alpha & .731 & .885 & .747 & .759 \\
\hline Eigenva & & 7.485 & 1.642 & 1.153 & 1.031 \\
\hline Percent & e of Variance Explained & 44.032 & 9.658 & 6.781 & 6.065 \\
\hline $\begin{array}{l}\text { Percent } \\
\text { KMO }=.\end{array}$ & $\begin{array}{l}\text { e of Total Variance Explained }=66.536 \\
39 ; \text { Bartlett s Test of Sphericity: } X 2=1340.856 ; \mathrm{DF}=136 ; \mathrm{p}=\end{array}$ & & & & \\
\hline
\end{tabular}

Source: Field Survey 
Structural Equation Model (SEM): SEM was used to evaluate the statistical significance of the research hypotheses. As proposed by Byrne (2016), the measurement model was performed before the structural or path model.

Measurement Model: The measurement model was performed via CFA by using SPSS Amos 22. The CFA aimed to confirm the findings of the EFA and also to assess the discriminant and convergent validity. First, to provide support for convergent validity, scale items with standardized regression weights below .50 were dropped (Hair et al., 2010). The findings of the CFA are displayed in Table 2 which revealed that 10 scale items loaded on their purported factors. The standardized regression weights of the 10 scale items were statistically significant, ranging from .676 to .867 . These findings confirmed convergent and discriminant validity (Kline, 2005). The Chi-square test (CMIN $=47.976, D F=29, p=.015$ ) was statistically significant and therefore, did not confirm the sampled data. However, other fit indexes strongly supported the measurement model. The Normed Chi-square test (CMIN/DF) of 1.654 was below three, indicating a better model fit (Hair et al., 2010). Likewise, the Incremental Fit Index (IFI), Comparative Fit Index (CFI), Relative Fit Index (RFI), Tucker-Lewis Index (TLI) and Normed Fit Index (NFI) were .976, .975, .909, .962 and .941, which are all higher than 0.90 respectively. This shows a good model fit (Hu \& Bentler, 1999; Hair et al., 2010). Lastly, the Root Mean Square Error of Approximation (RMSEA) was .067 with a 90\% confidence level falls between .30 and .10, which is less than .80, indicating a superior model fit (Hu \& Bentler, 1999). These findings suggest that the measurement model will provide better support to the path analysis.

\section{Findings}

Table 2: Findings of the Measurement Model

\begin{tabular}{lcc}
\hline Constructs and Scale Items & Standardized Regression Weights & t-values \\
\hline Perceived Usefulness & & \\
PER5 & .867 & $-\mathrm{a}$ \\
PER6 & .826 & 12.378 \\
PER7 & .844 & 12.801 \\
PER8 & .719 & 10.002 \\
Perceived ease of use & & \\
EAS 16 & .767 & 9.336 \\
EAS 17 & .797 & $-\mathrm{a}$ \\
Behavioural intentions to use & & \\
BEH 19 & .676 & $-\mathrm{a}$ \\
BEH 20 & .852 & 8.154 \\
Computer Education & & \\
LIT 1 & .785 & 6.719 \\
LIT3 & .763 & $-\mathrm{a}$ \\
\hline
\end{tabular}

Notes: $\mathbf{a}=$ path parameter was set to 1 , therefore not-values were estimated; all regression weights are significant at $\mathrm{p}=0.001$ level.

Construct Validity Test: Table 3 below depicts the results of construct validity statistics in the measurement model. Average Variance Extracted (AVE) was computed to further establish convergent validity in the CFA. The results indicate good convergent validity since all the AVEs of the factors were above .50 , which ranged between .560 and .666 (Fornell \& Larcker, 1981). Secondly, the square root of the AVEs of the factors was above the squared inter-factor correlations, which indicates independence between the factors (Bagozzi \& Yi, 1988; Fornell \& Lacker, 1981). This demonstrates that the construct validity of the CFA is acceptable which will offer a satisfactory analysis of the path model. 
Table 3: Results of the Construct Validity Test

\begin{tabular}{llcccc}
\hline Latent Constructs & AVE & $\begin{array}{c}\text { Perceived } \\
\text { Useful }\end{array}$ & $\begin{array}{c}\text { Perceived Ease } \\
\text { of Use }\end{array}$ & $\begin{array}{c}\text { Computer } \\
\text { Education }\end{array}$ & $\begin{array}{l}\text { Intention } \\
\text { to Use }\end{array}$ \\
\hline Perceived Usefulness & .666 & $.816^{* *}$ & & & \\
Perceived Ease of Use & .613 & .643 & $.783^{* *}$ & & \\
Computer Education & .560 & .445 & .295 & $.748^{* *}$ & \\
Intention to Use & .591 & .573 & .656 & .327 & $.769^{* *}$ \\
\hline
\end{tabular}

Notes: AVE = Average Variance Extracted; ${ }^{* *}$ Square root of AVEs; off-diagonal estimates display the squared inter-construct correlations.

Structural Model: The path model was employed to assess the hypotheses posited in this paper. Here, the computer education is specified as the independent variable, PEOU and PU are the mediating variables, whilst BITU is the dependent variable. Although, the Chi-square test (CMIN $=48.764, \mathrm{DF}=30, \mathrm{p}=.017$ ) failed to validate the path analysis, the other fit indexes were satisfactory; CMIN/DF = 1.625; RFI =. 911; TLI = .964; IFI $=.976 ; \mathrm{CFI}=.976$; NFI $=0.940 ; \mathrm{RMSEA}=.066$. The findings of the path model in Table 4 revealed that computer education has direct relationship with PEOU $(\beta=.570, \mathrm{t}=5.045, \mathrm{p}=.000)$ and PU $(\beta=.312, \mathrm{t}=$ $3.028, \mathrm{p}=.002)$ at significance levels of $\mathrm{p}<.001$ and .01 respectively. These findings confirm $H 1$ and $H 2$. In turn, PEOU has direct relationship with BITU $(\beta=.891, t=3.996, p=.000)$ and PU $(\beta=.624, t=5.530, p=$. $000)$ at significance level of $\mathrm{p}<.001$. These findings also confirm $H 3$ and $H 4$. Finally, although, the relationship between PU $(\beta=.046, t=.253, p=.800)$ and BITU is positive, it is not statistically significant. This outcome shows that $H 5$ is rejected.

Table 4: Findings of the Structural Model

\begin{tabular}{llccc}
\hline Hypotheses & Structural Relations & $\begin{array}{c}\text { Standardized } \\
\text { Estimates( } \boldsymbol{\beta})\end{array}$ & t-value & Results \\
\hline H1 & Perceive Ease of Use <---- Computer Education & .570 & 5.045 & Supported \\
H2 & Perceived Usefulness <----- Computer Education & .312 & 3.028 & Supported \\
H3 & Intention to Use <------- Perceived Ease of Use & .891 & 3.996 & Supported \\
H4 & Perceived Usefulness <--- Perceived Ease of Use & .624 & 5.530 & Supported \\
H5 & Intention to Use <-------- Perceived Usefulness & .046 & .253 & Unsupported \\
\hline
\end{tabular}

\section{Discussion}

This paper was set out to assess the role of computer education in the BITU IT systems in the hospitals in Kumasi. The research revealed that computer education contributes to increasing PEOU of IT systems in the hospitals in Kumasi. This result is similar to the findings of a prior study which indicates that computer education positively influences the PEOU of technology application (Burton-Jones \& Hubona, 2006). Thus, a high level of computer education potentially enhances the users' understanding and reduces their anxiety about using IT applications. In turn, PEOU directly affects PU and BITU the IT applications in the hospitals in the Metropolis. This result concurs with previous research which suggests that PU and BITU are positively influenced by PEOU of IT systems (Venkatesh \& Davis, 2000).

The adoption of an IT system is enhanced once the user understands and is comfortable with its usage. The user then appreciates the importance of the IT application of his job performance. Consequently, the user develops a positive attitude toward it and ultimately, the willingness to work with it. Consistent with past research (Burton-Jones \& Hubona, 2006), the study also found that staff computer education directly influences the PU of IT systems in the hospitals in the Metropolis. In essence, the extent of computer training the users have provides a platform for them to understand the importance of using IT applications in health care settings. Finally, the study also revealed that computer education commands a stronger influence on PEOU than the PU of IT systems in the hospitals in Kumasi.

Recommendations: Guided by the findings of the research, the recommendations made are as follows;

- First, the research confirmed that computer education positively influences PEOU and in turn, drives BITU IT systems in the hospitals in Kumasi. It is therefore recommended that management should offer 
regular computer training to staff to enhance PEOU which in turn, will increase their BITU in the hospitals in the Metropolis.

- The research also established that PU of IT applications is directly influenced by computer education in the hospitals in Kumasi. Therefore, management should concentrate their efforts to improve computer education to enrich staff PU of IT systems in the hospitals in Kumasi.

- Furthermore, the research demonstrates that PEOU positively affects staff PU of IT applications in the hospitals in Kumasi. Consequently, management should make the use of IT systems less effortful and comfortable to staff to enhance their PU in the hospitals in the Metropolis.

- Finally, the research also revealed that computer education commands a greater influence on PEOU than the PU of IT applications in the hospitals in the Metropolis. Recognizing the dominant impact of computer education on PEOU of IT applications, management should focus on computer training to greatly enrich the staff understanding and comfortability in using IT applications in the hospitals within the Metropolis.

\section{Conclusion}

This paper was set out to evaluate the potential role of computer education in the BITU IT applications in the hospitals in Kumasi Metropolis. More specifically, this paper aimed to investigate the significance of computer education to PEOU and PU and in turn, their impact on BITU IT applications in healthcare organizations. The findings of the research demonstrate that computer education has a stronger impact on PEOU and hence, the BITU IT systems in the hospitals in the Metropolis. This confirms that workers' level of knowledge in IT determines their willingness to adopt IT systems to support health care delivery in the Metropolis. Furthermore, the research revealed that computer education directly influences PU and indirectly, through PEOU of IT systems in the hospitals. Thus, the research establishes that the usage of IT becomes effortless and useful to workers if they are properly trained in IT systems. This paper, therefore, confirmed the conceptualization of Burton-Jones and Hubona (2006), which suggested that computer education is one of the essential antecedents of users` PEOU and PU in the adoption of IT systems in an organization. However, PEOU was identified as the key determinant of BITU IT systems in the hospitals in Kumasi.

Limitations and Future Research: This paper is not free from limitations that necessitate further studies to strengthen its generalization. Geographically, the research was confined to healthcare facilities in Kumasi which may limit its generalization to other parts of the country. Future research should include healthcare facilities drawn from the rest of the country to enrich the generalization of the current research. In addition, quantitative research methods were used where closed-ended questions were utilized to ascertain the PU, PEOU, BITU, and the level of computer education. It is recommended that the qualitative approach should be considered in the future to permit a comprehensive study of the level of staff computer education, PEOU, PU, and BITU IT applications in the healthcare organizations in Kumasi and Ghana as a whole.

\section{References}

Abookire, S. A., Teich, J. M., Sandige, H., Paterno, M. D., Martin, M. T., Kuperman, G. J. \& Bates, D. W. (2000). Improving allergy alerting in a computerized physician order entry system. Paper presented at AMIA Symposium (https://www.ncbi.nlm.nih.gov/pmc/articles/PMC2243998/pdf/procamiasymp00 0030037.pdf: Accessed October 2018).

AbuShanab, E. \& Pearson, J. M. (2007). Internet banking in Jordan: The unified theory of acceptance and use of technology (UTAUT) perspective. Journal of System Information Technology, 9(1), 78-97.

Ajami, S. \& Arab-Chadegani, R. (2013). What are the most important barriers to implement Radio Frequency Identification Device (RFID) in Health System? Journal of Information Technology Software Engineering, 4(7), 7- 19.

Ajzen, I. (1991). The theory of planned behaviour. Organizational Behaviour and Human Decision Processes, $50(2), 179-211$.

Al-Gahtani, S. S. \& King, M. (1999). Attitudes, satisfaction and usage: factors contributing to each in the acceptance of information technology. Behaviour Information Technology, 18(4), 277- 297.

Atilgan, E., Aksoy, S. \& Akinci, S. (2005). Determinants of Brand Equity: A Verification Approach in the Beverage Industry in Turkey. Marketing Intelligence \& Planning, 23(3), 237- 248. 
Bagozzi, R. P. \& Yi, Y. (1988). On the Evaluating Structural Equation Models. Journal of Academy of Marketing Research, 16(1), 074-094.

Burton-Jones, A. \& Hubona, G. S. (2006). The mediation of external variables in the technology acceptance model. Information \& Management, 43, $706-717$.

Byrne, B. M. (2016). Structural Equation Modeling with AMOS: Basic Concepts, Applications and Programming (3rd ed.), New York: Taylor \& Francis.

Creswell, J. W. (2014). Research Design: Qualitative, Quantitative, and Mixed Methods Approaches (4th ed.), California: SAGE Publications Inc.

Davis, F. D. (1989). Perceived usefulness, perceived ease of use and user acceptance of information technology. Management Information Systems Quarterly, 13, 319-339.

Davis, F. D. \& Venkatesh, V. (1996). A critical assessment of potential measurement biases in the technology acceptance model: three experiments. International Journal of Human-Computer Studies, 45, 19-45.

dos Reis, R. A. \& Freitas, M. d. C. D. (2014). Critical Factors on Information Technology Acceptance and Use: An Analysis of Small and Medium Brazilian Clothing Industries. Information Technology and Quantitative Management, 31, 105-114.

Floyd, F. J. \& Widaman, K. F. (1995). Factor Analysis in the Development and Refinement of Clinical Assessment Instrument. Psychological Assessment, 7(3), 286-299.

Fornell, C. \& Larcker, D. F. (1981). Evaluating Structural Equation Models with Unobservable Variables and Measurement Error. Journal of Marketing Research, 18(1), 39-50.

Hair, J. H., Black, W. C., Babin, B. J. \& Anderson, R. E. (2010). Multivariate Data Analysis: A Global Perspective (7th ed.), New York: Pearson Prentice Hall.

Handy, J., Hunter, I. \& Whiddat, R. (2001). User Acceptance of inter-organizational electronic medical records. Australasian Journal of Information Systems, 7(2), 103-107.

Hu, L. \& Bentler, P. M. (1999). Cut-off Criteria for Fit Indexes in Covariance Structure Analysis: Conventional Criteria versus New Alternatives. Structural Equation Modeling Multidisciplinary Journal, 6 (1), 1- 55.

Hennington, A. \& Janz, B. D. (2007). Information systems and healthcare XVI: physician adoption of electronic medical records: applying the UTAUT model in a healthcare context. Journal of Health Management, 19(5), 243-269.

Johnson, R. (2003). Health Care Technology: A history of clinical care innovation, USA: Washington National Press.

Kaye, R., Kokia, E., Shalev, V., Idar, D. \& Chinita, D. (2010). Barriers and success factors in health information technology; A practitioner's perspective. Journal of Management \& Marketing in Healthcare, 3(3), 163-175.

Kijsanayotin, B., Pannarunothai, S. \& Speedie, S. M. (2009). Factors influencing health information technology adoption in Thailand's community health centres: Applying the UTAUT model. International Journal of Medical Information, 78(6), 404-416.

Kline, R. B. (2005). Principles and Practice of Structural Equation Modelling (2nd ed.), New York: Guilford Press.

KMA. (2018). Republic of Ghana: The Composite Budget of Kumasi Metropolitan Assembly for 2018 Fiscal Year (http://www.mofep.gov.gh/sites/default/files/budget/2014/AR/kumasi.pdf: Accessed September 2018).

Krejcie, R. V. \& Morgan, D. W. (1970). Determining Sample Size for Research Activities. Educational \& Psychological Measurement, 30, 607-610.

Laudon, K. C. \& Laudon, J. P. (2000). Essentials of Management Information Systems: Managing the Digital Firm (5 ${ }^{\text {th }}$ ed.), New York: Pearson Education Inc.

Lean, O. K., Zailani, S., Ramayah, T. \& Fernando, Y. (2009). Factors influencing intention to use e-government services among citizens in Malaysia. International Journal of Information Management, 29(6), 458475.

Legris, P., Ingham, J. \& Collerate, P. (2003). Why do people use information technology? A critical review of the technology acceptance model. Information \& Management, 40(3), 191-204.

Mackenzie, N. \& Knipe, S. (2006). Research Dilemmas: Paradigms, Methods and Methodology. Issues in Educational Research, 16, 193-205.

Malhotra, N. K. \& Birks, D. F. (2007). Marketing Research: An Applied Approach (3 ${ }^{\text {rd }}$ ed.), England: Pearson Education Limited.

Miles, M. B. \& Huberman, A. M. (1994). Qualitative Data Analysis, New Delhi: SAGE Publications. 
Miller, M. R., Elixhauser, A., Zhan, C. \& Meyer, G. S. (2001). Patient safety indicators: Using administrative data to identify potential patient safety concerns. Health Services Research, 36(2), 110-132.

$\mathrm{MOH}$ (2009). Ghana e-health strategy (https://www.isfteh.org/files/media/ghana_national_ehealth_strategy.pdf: Accessed September 2018).

Noblin, A. M., Wan, T. T. H. \& Fottler, M. (2013). Intention to use a personal health record: a theoretical analysis using the technology acceptance model. International Journal of Healthcare, Technology \& Management, 14(2), 73-89.

Oppong, P. K. \& Phiri, M A. (2019). The Link between Brand Equity and Loyalty: Evidence from Traditional Medicine Market in Kumasi Metropolis, Ghana. Journal of Economics and Behavioral Studies, 11(1), 11-21.

Pallant, J. (2013). SPSS Survival Manual: A Step by Step Guide to Data Analysis using IBM SPSS (5 $5^{\text {th }}$ ed.), New York: McGraw-Hill Education.

Peker, C. (2010). An Analysis of the Main Critical Factors that Affect the Acceptance of Technology in Hospital Management Systems (Unpublished Doctoral Thesis). Middle East Technical University, Turkey (https://etd.lib.metu.edu.tr/upload/12612453/index.pdf: Accessed June 2018).

Stol, I. S., Ehrenfeld, J. M. \& Epstein, R. H. (2014). Technology diffusion of anesthesia information management systems into academic anesthesia departments in the United States. Anesthesia \& Analgesia, 118(3), 644-650.

Surendran, P. (2012). Technology Acceptance Model: A Survey of Literature. International Journal of Business \& Social Research, 2(4), 175-178.

Tavakol, M. \& Dennick, R. (2011). Making Sense of Cronbach`s Alpha. International Journal of Medical Education, 2, 53-55.

Venkatesh, V. \& Davis, F. D. (2000). A theoretical extension of the technology acceptance model: four longitudinal field studies. Management Science, 46(2), 186-204.

Wu, J. H., Wang, S. C. \& Lin, L. M. (2007). Mobile computing acceptance factors in the healthcare industry: A structural equation model. International Journal of Medical Information, 76, 66-77. 